WEINTRAUB, D. J., \& MchaLE, T. J. Apparent verticality: Psychophysical error versus sensory-tonic theory. Journal of Experimental Psychology, 1967, 73, 347-353.

SCHONE, $H$. On the role of gravity in human spatial orientation. Aerospace Medicine, 1964, 35, 764-772.

WADE, N. J. The effect of stimulus line variations on visual orientation with head upright and tilted. Australian Joumal of Psychology, 1969a, 21, 177-185.

WADE, N. J. Visual orientation as a function of head tilt. Perceptual \& Motor Skills, 1969b, 29, 573-574.

WADE, N. J., \& DAY, R. H. Development and dissipation of a visual spatial aftereffect from prolonged head tilt. Journal of Experimental Psychology, 1968, 76, 439-443.

WAPNER, S., \& WERNER, H. Perceptual development. Worcester, Mass: Clark University Press, 1957.

WEINTRAUB, D. J., O'CONNELL, D. C., \& McHALE, T. J. Apparent verticality: Fundamental variables of sensory-tonic theory reinvestigated. Joumal of Experimental Psychology, 1964, 68, 550-554.

WENDEROTH, P. M., CURTHOYS, I. S., \& RODGER, R. S. Confounding of psychophysical errors and sensory effects in adjustment measures of spatial aftereffects. Perception \& Psychophysics, 1968, 4, 133-138.

WETHERILI, G. B. Sequential estimation of quantal response curves. Joumal of the Royal Statistical Society, 1963, 25, 1-48. NOTES

1. Present address: Max-Planck-Institut : für Verhaltensphysiologie, 8131 Seewiesen, Germany.

2. Unpublished data indicate that changes in visual orientation during prolonged head tilt have similar spatial and temporal characteristics to those following tilt. That is, the E-effect for 30-deg head tilt is reduced by about 2 deg with prolonged tilt, and this adaptation develops within the first few minutes of tilt. Furthermore, the adaptation effect measured during tilt was similar when using both the adjustment and up-and-down methods.

\title{
The effect of a mnemonic device on retention of verbal material
}

\author{
JAMES R. PASH and KENNETH A. \\ BLICK, University of Richmond, Va. \\ 23173
}

\begin{abstract}
After $48 h$, the retention of two lists of nine words, one list containing high meaningful words, the other low meaningful words, was compared for a group that was instructed in the use of a mnemonic device and a group that received no such instruction. The mnemonic group was instructed that the initial letters of the nine words could be arranged to spell the word "education." Overall, the high meaningful list gave superior retention, and Ss who employed the mnemonic device showed superior retention, but the general method effect was not significant.
\end{abstract}

There has been little systematic investigation concerning the alleged utility of mnemonic devices in the retention of verbal material. Senter \& Hauser (1968) evaluated a commercial technique known as the hook or peg system. The hook technique involves the overlearning of an ordered series of verbal pegs, usually common English nouns; then it becomes possible to remember a new series of words by forming images associating the new word with the previously memorized pegs. If the peg words are thoroughly overlearned, and if the associative images are sufficiently well formed, any word in the newly learned list can be recalled. Senter \& Hauser (1968) found that Ss trained with the hook system produced more correct anticipations during serial learning of $20 \mathrm{CVCs}$ than untrained Ss. Earlier, Smith \& Noble (1965) had reported similar acquisition data and noted that the peg system was more effective on retention tests with low meaningful material than with material of either high or medium meaningfulness.

The purpose of the present experiment was to examine the effectiveness of the first letter technique, a mnemonic device whereby the first letters of the words to be remembered can be arranged to spell a meaningful word. It was hypothesized that retention would be facilitated for Ss using the first letter technique, and the mnemonic device would be more effective with low meaningful material than with high meaningful material.

\section{METHOD}

The Ss were 96 students in two introductory psychology classes at the University of Richmond. One class of $56 \mathrm{Ss}$ was exposed to the mnemonic device and another class of $40 \mathrm{Ss}$ served as a control group. Within each group, approximately half of the Ss received high meaningful material and half received low meaningful material.

Two lists were prepared using 18 dissyllables selected from Noble's (1952) $m$ scale. The low meaningful list ( $m$ value $=1.89$ ) contained the following items: NEGLAN, TUMBRIL, ULNA, ICON, DAVIT, ATTAR, CAROM,
ENDIVE, and OVUM. The high meaningful list (m-value $=6.91$ ) consisted of: NAPHTHA, TYPHOON, UNCLE, INSECT, DINNER, ARMY, CAPTAIN, EFFORT, and OFFICE. The material was presented to the Ss in the form of a test booklet. The first page was a cover sheet, the second page contained the nine items in the same order as shown above, and the third page was the test sheet. At the start the Ss were told, "The purpose of this experiment is to determine whether or not you can memorize nine words in five minutes. At the end of five minutes you will be given two minutes to write as many of the words as you can remember. The words do not have to be written in the same order as they appear on the sheet." At this point, one class was told that the first letters of the nine words they were going to memorize could be arranged to spell the word "education" and that using this mnemonic device should help them remember the words. The control condition, of course, was not made aware of mnemonic technique. The Ss were not advised that they would be tested again; however, $48 \mathrm{~h}$ later they were tested for retention of the nine items.

\section{RESULTS}

Table 1 shows the nercentage correct recall for the immediate and 48-h retention tests. The columns indicate whether or not the instruction was given in the use of the mnemonic device, and the rows indicate the level of meaningfulness. The first value in the not-instructed column, 96 , means that the group correctly recalled $96 \%$ of the maximum number of correct responses for that group (162), which was determined by multiplying the number of Ss in the group $(\mathrm{N}=18)$ by the number of words to be memorized (9).

Table 2 presents the results of the statistical comparisons of the values presented in Table 1. The comparisons were made by testing for the significance of the differences between percentages, with the first eight comparisons for uncorrelated data and the last four for correlated data. All tests were of the one-tail variety at the $1 \%$ level of significance. Note that the third and fourth comparisons indicate that, even after $48 \mathrm{~h}$, instruction in the use of the mnemonic device did not significantly improve retention of either high or low meaningful lists. As was expected, there was a significant retention loss over $48 \mathrm{~h}$, as shown by the last four comparisons, and high meaningful material was retained at a significantly higher level than low meaningful material at $48 \mathrm{~h}$, as shown by Comparisons 7 and 8.

\section{DISCUSSION}

The original hypothesis concerning the 
Table 1

Percentage of Correct Recall Responses for Immediate and 48-H Retention Intervals

\begin{tabular}{|c|c|c|c|}
\hline \multirow[b]{2}{*}{$\begin{array}{c}\text { Meaning- } \\
\text { fulness }\end{array}$} & \multirow[b]{2}{*}{$\begin{array}{c}\begin{array}{c}\text { Retention } \\
\text { Interval }\end{array} \\
\end{array}$} & \multicolumn{2}{|c|}{ Mnemonic Device } \\
\hline & & $\begin{array}{c}\text { Not } \\
\text { Instructed }\end{array}$ & Instructed \\
\hline Low & $\begin{array}{l}\text { Immediate } \\
48 \text { Hours }\end{array}$ & $\begin{array}{l}96 \\
68\end{array}$ & $\begin{array}{l}95 \\
70\end{array}$ \\
\hline High & $\begin{array}{l}\text { Immediate } \\
48 \text { Hours }\end{array}$ & $\begin{array}{l}99 \\
87\end{array}$ & $\begin{array}{l}97 \\
88\end{array}$ \\
\hline
\end{tabular}

Table 2

Results of Statistical Comparisons of Values Presented in Table 1

\begin{tabular}{ccc}
\hline Factors & $\begin{array}{c}\text { Values } \\
\text { Compared }\end{array}$ & $\begin{array}{c}\mathrm{z} \\
\text { Value }\end{array}$ \\
\hline Mnemonic & $96-95$ & 0.50 \\
Device & $99-97$ & 1.54 \\
& $68-70$ & 1.33 \\
& $87-88$ & 1.00 \\
Meaning- & $96-99$ & 1.76 \\
fulness & $95-97$ & 1.18 \\
& $68-87$ & $4.75^{*}$ \\
& $70-88$ & $5.14^{*}$ \\
Retention & $96-68$ & $3.46^{*}$ \\
Interval & $95-70$ & $4.12^{*}$ \\
& $99-87$ & $3.00^{*}$ \\
\hline
\end{tabular}

* Significant at $1 \%$ level

facilitating effect of the first letter technique was only partially confirmed. Certainly a most surprising finding was that only $25 \%$ (14 out of 56 ) of the Ss in the mnemonic condition obviously used the first letter technique when they attempted to recall the nine words. True, their retention-level was significantly higher than apparent nonusers, but it definitely raises the question of why more Ss did not use the mnemonic device. One reason for their reluctance to employ the first letter technique could be that the list was so short and simple that no memory aid was deemed necessary. Another reason could be that some $S s$ in the experimental condition refused to apply a novel mnemonic technique in place of some overlearned memory aid of their own. Also, it is possible that the amount of training given the "instructed" group may have been inadequate to produce significant facilitation. During recall, Ss should be required to write down the first letters and then recall the words.

Perhaps what is now needed in the area of mnemonics is a survey to find out just what mnemonic devices are employed by learners when they are given a reasonably difficult task to learn and remember. Following the discovery and classification of these memory aids, research can be conducted to determine their overall effectiveness.

Another finding of primary interest is that of the $56 \mathrm{Ss}$ in the mnemonic condition, only 14 obviously used the first-letter technique; that is, either the order of their responses on the test was such that the initial letters spelled "education" or they wrote "education" on the test sheet during recall. The level of recall after $48 \mathrm{~h}$ for these 14 Ss was $89 \%$ compared to $74 \%$ for the remaining 42 Ss in the mnemonic condition, and the difference in percent recall is highly significant $(z=13.64, \quad p<.01)$. Similar results were obtained by comparing the retention level of the 14 "users" to the retention level of $78 \%$ of the control group. Again, the difference was highly significant $(z=10.00, p<.01)$ in favor of the Ss who used the mnemonic device.

\section{REFERENCES}

NOBLE, C. E. An analysis of meaning Psychological Review, 1952, 59, 421-430.

SENTER, R. J., \& HAUSER, G. K. An experimental study of a mnemonic system. Psychonomic Science, 1968, 10, 289-290.

SMITH, R. K., \& NOBLE, C. E. Effects of a mnemonic technique applied to verbal learning and memory. Perceptual \& Motor Skills, 1965 . 21, 123-134. 